\title{
O DIÁLOGO EM PROCESSOS DE POLÍTICAS PÚBLICAS DE EDUCAÇÃO AMBIENTAL NO BRASIL
}

\author{
DANIEL FonseCA DE ANDRADE* \\ ANDRÉA QUIRINO DE LUCA* \\ MARCOS SORRENTINO ${ }^{* * *}$
}

\begin{abstract}
RESUMO: Políticas públicas de educação ambiental no Brasil estimulam o envolvimento de educadores em processos de políticas públicas mediados pelo diálogo. Isso demanda o desvelamento do conceito de diálogo, objetivo deste trabalho. Os resultados do levantamento bibliográfico estabelecem a relação entre o diálogo, as políticas públicas de educação ambiental e seus pressupostos epistemológicos, trazem a fundamentação filosófica e abordam a teoria operacional para o diálogo. Por fim, indicam obstáculos a sua ocorrência e sugerem a formação de espaços de diálogo para contorná-los.
\end{abstract}

Palavras-chave: Educação ambiental. Programa Nacional de Educação Ambiental. Diálogo. Políticas públicas.

\section{DiALOGUE IN PROCESSES OF ENVIRONMENTAL EDUCATION OF PUBLIC POLITICS IN BRAZIL}

ABSTRACT: Brazilian environmental education public politics encourage educators to get involved in processes of public politics mediated through dialogue. This demands an enquiry into the concept, the objective of this essay. The results of the bibliographical review establish the connection between dialogue, environmental education public policies and their epistemological presuppositions, outline the philosophical groundings and approach the operational theory of dialogue. In the end, they indicate obstacles to its emergence and suggest the formation of spaces of dialogue to get around them.

Key words: Environmental education. National Programme of Environmental Education. Dialogue. Public politics.

\footnotetext{
* Doutorando no Programa de Ciência Ambiental da Universidade de São Paulo (USP) e pesquisador do Laboratório de Educação e Política Ambiental (OCA) da Escola Superior de Agricultura Luiz de Queiroz (Esalq/USP, Piracicaba). E-mail: dfa@netsite.com.br

* Doutoranda no Programa de Ciência Ambiental da USP e Pesquisadora do Laboratório OCA. E-mail: andreaqluca@gmail.com

*** Doutor em Educação, professor do Departamento de Ciências Florestais da Esalq/USP e Coordenador do Laboratório OCA. E-mail: marcossorrentino@yahoo.com.br
} 


\section{LE DiAlogue SUR LES PROCESSUS DE POLITIQUES PUbLIQUES DE L'ÉDUCATION ENVIRONNEMENTALE AU BRÉSIL}

RÉSUMÉ: Les politiques publiques pour l'éducation environnementale au Brésil encouragent la participation des éducateurs dans les processus de politiques publiques médiées par le dialogue. Cela exige le dévoilement du concept, but de cette étude. Les résultats du recensement bibliographique établissent la relation entre le dialogue, les politiques publiques pour l'éducation environnementale et leurs présupposés épistémologiques, apportent le fondement philosophique et abordent la théorie opérationnelle pour le dialogue. Enfin, ils indiquent les obstacles à son avènement et proposent la formation d'espaces de dialogue pour les contourner.

Mots-clés: Éducation environnementale. Programme National pour l’Education Environnementale. Dialogue. Politiques publiques.

\section{Epistemologia e políticas públicas}

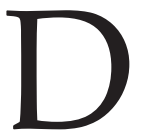

e acordo com Ramos (2009), uma análise sobre os pressupostos epistemológicos que embasam processos de decisão, delineamento e implantação de políticas públicas apontará para uma polarização ${ }^{1}$ de visões de mundo acerca do fenômeno da modernização. Um dos extremos dessa oposição decorre e, portanto, operacionaliza o próprio discurso caracterizador da modernidade, que reconhece o futuro como uma possibilidade única, uma "necessidade histórica" rumo a um "arquétipo platônico" (p. 43) de sociedade, posição ocupada pela Europa ocidental ou os Estados Unidos. O outro se baseia na inexistência de um modelo civilizatório único e nas possibilidades próprias de modernização para as nações.

Para o autor, o primeiro extremo abordado parte de uma avaliação reducionista da realidade, apoiada no cogito cartesiano (Rezende, 2009) que, segundo Morin (2001), promove a fragmentação e a linearização do pensamento; a simplificação e a purificação da realidade; a separação entre sujeito e objeto e a busca por leis gerais e ordem no universo.

O segundo extremo parte de uma visão complexa de mundo e compreende o futuro como possibilidade, ou seja, vê o processo social como uma "resultante contínua de uma tensão dialética entre determinismo e liberdade" (Ramos, 2009, p. 46). Assim, reconhece o curso dos acontecimentos como um jogo de fatores objetivos e opções humanas e, portanto, a importância das diferentes subjetividades - individuais e coletivas - na constituição de uma sociedade (Ramos, op. cit.; Rezende, 2009).

A bifurcação ora demarcada se estende também até a percepção do papel do Estado na sociedade. Nesse caso, dentro da lógica moderna, o Estado é capaz, sozinho, de administrar o bem comum. Do outro lado, argumenta-se que não é possível 
para a sociedade depender de um governo para oferecer os serviços de que necessita, cabendo assim a outros atores estabelecer uma relação de corresponsabilidade com ele na gestão do bem público (Heidemann, 2009), delineando uma sociedade multicêntrica, constituída por diferentes enclaves (Salm, 2009).

Isso pressupõe não só o reconhecimento das limitações dos discursos monótonos diante da complexidade da realidade e da dimensão dos desafios que se colocam atualmente - inclusive socioambientais -, mas também da crescente percepção sobre a incapacidade de uma única tradição cultural produzir as respostas para essas questões. Ao contrário, os adeptos dessa visão de mundo consideram importante o incentivo ao diálogo entre diferentes saberes, como forma de se trazer para a conversa aspectos importantes que, de outra maneira, poderiam ser deixados de fora (Funtowics \& Ravetz, 2000).

Ao se estabelecer, no entanto, a opção pela participação social na construção de políticas públicas, encontra-se um novo obstáculo, que é a ausência de espaços que garantam tal participação.

De acordo com Salm (2009), a era moderna definiu a burocracia como a instância de construção do bem público. Ainda segundo o autor, nos tempos atuais a burocracia pública está sendo substituída pela privada a serviço do livre mercado na construção do bem comum. Ao se questionar sobre a existência de "alternativas para a produção do bem público que transcendam o fatalismo entre a estatização e a privatização" (p. 88), indica que nelas haveria o "auxílio de estratégias que permitam articular as forças da sociedade" (p. 89). Isso não significa a eliminação dessas formas de burocracia, mas uma convivência isonômica com outras formas de produção do bem público.

Assim, Salm (op. cit.) defende que o estabelecimento de espaços de participação, além de proporcionar um local em que uma questão determinada possa ser olhada a partir de várias perspectivas, é também um mecanismo para se desburocratizar a construção do bem comum. Para Heidemann (2009), estes espaços podem ainda exercer uma importante função nos próprios processos de políticas públicas.

Como mostra Frey (2000), são vários os modelos de análise de políticas públicas disponíveis, cada um deles contendo limitações e também oferecendo referenciais importantes para a compreensão dos processos. Um desses modelos, o de ciclo da política, ${ }^{2}$ é destacado pelo autor por permitir uma "análise da vida de uma política pública" (p. 226), ou seja, contempla o dinamismo do processo ao longo do tempo.

Embora as etapas presentes nesses ciclos demonstrem pequenas variações de autor para autor (ver, por exemplo, Heidemann, 2009; Frey, 2000; Souza, 2006), em geral, podem ser definidas como: a tomada de decisões e a formulação, a implantação 
da política, a verificação da satisfação dos interesses das partes e a sua avaliação (Heidemann, 2009). Por muito tempo, o foco de ação das pesquisas se deu predominantemente sobre a tomada de decisões e formulação da política, considerando-se que, uma vez tomada a decisão, seu impacto seria automático. A ideia de que é necessário um esforço na fase de implantação da política é mais recente e continua sendo alvo de estudos (idem, ibid.).

Cline (2000), por exemplo, compara duas tendências científicas na definição da questão da implantação de políticas públicas. A primeira considera a implantação como um processo administrativo e tem seu foco na habilidade de uma única estrutura gerenciá-lo e, na segunda, o processo é visto como um conflito de interesses. Nesse caso, os problemas do processo de implementação derivariam exatamente desse conflito de valores, e a solução poderia ser encontrada na construção de "instituições ou mecanismos que criem um contexto cooperativo para aqueles que participam do processo de implementação" (p. 552). Ao final, o autor conclui que a primeira tendência oferece uma visão restrita e centralizada do processo de implantação e negligencia os aspectos relacionados aos conflitos. Já a segunda acerta ao considerar o conflito de interesses que cerca os atores do processo, inserindo-os dentro de seus contextos políticos e sociais mais amplos, bem como em suas redes de relações. Ao definir, portanto, a cooperação como um pressuposto fundamental na implementação bem sucedida de uma política, considera igualmente essencial uma "abordagem decisória de natureza participativa e dialógica" (Heidemann, 2009, p. 37).

\section{A educação ambiental como política pública no Brasil}

O histórico de criação de políticas públicas de educação ambiental (EA) em âmbito federal no Brasil iniciou-se em 1973 com a criação da Secretaria Especial de Meio Ambiente (Sema), que tinha como uma de suas atribuições "o esclarecimento e a educação do povo brasileiro para o uso adequado dos recursos naturais, tendo em vista a conservação do meio ambiente" (Brasil, 2005, p. 22).

Foi apenas em 1981, no entanto, que a EA apareceu pela primeira vez em um marco legal federal, inserida como um princípio da Política Nacional do Meio Ambiente (Brasil, 1981). Posteriormente, em 1988, teve a sua importância reforçada ao ser destacada na Constituição Federal, como uma forma de se assegurar o direito de todos ao meio ambiente ecologicamente equilibrado e também de defesa e preservação ambiental para as gerações presentes e futuras (Brasil, 1988).

Na década de 1990, com as influências pré e pós-Eco-92, a EA passou a se fazer mais presente em diferentes instâncias governamentais, como no Ministério da Educação (Medina, 1997) e no nascente Ministério do Meio Ambiente. Em 1994, 
apoiando esse fortalecimento, o governo federal criou o Programa Nacional de Educação Ambiental, documento que ao longo de sua história estará sujeito a constantes revisões públicas (Brasil, 2005).

Ao mesmo tempo em que ocorreu a sua incorporação na dimensão governamental brasileira, houve um envolvimento maior da EA tanto junto à academia quanto à sociedade civil, com consequente aumento do número de trabalhos acadêmicos, ocorrência de encontros e fóruns (Reigota, 1998) e multiplicação das redes. ${ }^{3}$

Foi no contexto da sociedade civil, no Fórum das ONGs, realizado na Rio-92, que nasceu o Tratado de Educação Ambiental para Sociedades Sustentáveis e Responsabilidade Global (Fórum Internacional de Organizações Não Governamentais e Movimentos Sociais, 1992), documento construído a muitas mãos e que até os dias atuais é referência fundamental para as políticas públicas de EA do Brasil (Sorrentino et al., 2007).

Esse novo arranjo da EA no país - caracterizado pelo surgimento e multiplicação de atores, pela ampliação de seu espaço nas instituições públicas e a existência de um Programa Nacional - culminou, ao final da década de 1990, na criação da Política Nacional de Educação Ambiental (PNEA) (Brasil, 1999), que legitimou o direito de acesso de todos à EA e aos princípios da sustentabilidade (Sorrentino et al., 2007). A regulamentação da PNEA, por sua vez, definiu a composição e as competências de seu órgão gestor e comitê assessor, garantindo os sustentáculos para a sua execução, ocorrida em junho de 2003 (Brasil, 2005).

Em 2005, foi publicada a terceira versão do novo Programa Nacional de Educação Ambiental (Pronea), cujas diretrizes indicam que a pluralidade social brasileira deve ser expressa nos processos de educação ambiental locais, sem prescrições impostas pelos órgãos federais, estaduais ou municipais. Com isso, o programa estimula a articulação de educadoras e educadores ambientais; instituições públicas e privadas; coletivos e redes para a produção de políticas públicas capilarizadas, que atinjam a totalidade da população do país (Brasil, 2006a). Tal princípio, decorrente do Tratado de EA, permeará todos os subprogramas e projetos do Pronea (Brasil, 2005).

Um desses subprogramas, o Programa Nacional de Formação de Educadoras(es) Ambientais: por um Brasil Educado e Educando Ambientalmente para a Sustentabilidade (Profea), explicita tal intencionalidade ao afirmar que a pretensão do documento é:

(...) qualificar as políticas públicas federais de educação ambiental para que exijam menos intervenções diretas e ofereçam mais apoio supletivo às reflexões e ações autogeridas regionalmente, no sentido de desenvolver uma dinâmica nacional contínua e sustentável de processos de formação de educadoras(es) ambientais a partir de diferentes contextos. (Brasil, 2006b, p. 5) 
No entanto, o contexto trazido pelo Pronea, que pressupõe processos de delineamento e implantação de políticas públicas em EA de forma participativa e dialógica, insere educadores e educadoras ambientais em um novo universo de atuação. Para além dos projetos pontuais, é necessário que sejam capazes de pensar a EA para a totalidade de um território. Pensar a educação ambiental como política pública, porém, demanda um rol de conhecimentos teóricos e metodológicos que, em geral, não faz parte de suas formações (Sorrentino \& Nascimento, 2010). Uma das questões importantes desse arcabouço, e que teve sua centralidade demonstrada nas duas partes iniciais deste trabalho, diz respeito à melhor compreensão acerca de alguns aspectos que são específicos sobre o diálogo.

\section{O diálogo}

Conforme já observado, o Pronea se insere em uma corrente epistemológica de construção de políticas públicas que dá reconhecimento e valorização para a pluralidade social existente no país. Considera, ainda, que o próprio processo de constituição e implantação das políticas deva não só fomentar sua participação, mas também, através disso, fortalecer essa pluralidade. Ou seja, localizar, dar visibilidade e credibilidade a experiências sociais ricas, mas que são "desperdiçadas", sendo silenciadas ou apagadas da realidade (Santos, 2002).

Como coloca o autor em outro momento (Santos, 2003), ao invés de escolher um percurso único de futuro, irracional, este processo deve estimular a emergência das múltiplas minirracionalidades, de forma que elas "deixem de ser partes de um todo e passem a ser totalidades presentes em múltiplas partes" (p. 102). Tanto o Pronea quanto a corrente epistemológica na qual ele se insere conferem grande importância à prática do diálogo em processos de políticas públicas.

A justificativa para a centralidade do diálogo deriva do conhecimento das limitações de processos não dialógicos de construção de políticas públicas, que podem ser observados tanto em âmbito internacional (Spink, 2003) quanto nacional (Castellano \& Sorrentino, 2012). Coerente com sua proposta, o próprio Pronea (Brasil, 2005) decorre de processos dialógicos, conforme enuncia: "A presente versão é resultado de processo de Consulta Pública (...) que envolveu mais de 800 educadores ambientais de 22 unidades federativas do país (...)", e reafirma ao estabelecer seu estado de permanente construção.

Portanto, essa importância atribuída ao conceito exige uma investigação mais profunda sobre ele, para que sejam evitadas confusões semânticas com outras formas de conversas (Yankelovich, 2001). 
Neste trabalho, o embasamento filosófico para o conceito de diálogo provém de Buber (1979), para quem, diferentemente do cogito cartesiano, a própria existência se dá no diálogo, naquele tipo de relação em que há o encontro genuíno entre as totalidades dos homens, suas essências (Zuben, 1979).

De acordo com Buber (op. cit.), as atitudes com as quais os homens se colocam diante do mundo permitem dois tipos de relação, que podem, por sua vez, ser estabelecidas com a natureza, com outros homens e com seres espirituais. Tais formas de relação são nomeadas por ele por palavras-princípio: Eu-Tu e Eu-Isso.

A relação Eu-Tu é aquela estabelecida sem obstáculos ao encontro das essências dos seres e ocorre quando, entre eles, não há "nenhum jogo de conceitos, nenhum esquema, nenhuma necessidade, nenhuma fantasia" (idem, ibid., p. 13). Esse tipo de relação reconhece a exclusividade do outro, sua distinção e humanidade ilimitados. É o que Brandão (2007, p. 4) chama de "aura", ou seja, a "absoluta singularidade", quando se reconhece o ser em si mesmo, "até quando é uma flor entre outras de uma árvore entre milhares, de uma floresta (...)".

A relação Eu-Tu se dá no tempo presente, "não no sentido de instante pontual que não designa senão o término, (...) mas o instante atual e plenamente presente" (Buber, 1979, p. 14), e na reciprocidade do encontro. O Eu da relação só o será quando o Tu o for, de forma que a humanidade de Eu e Tu só ocorre mutualmente. O "Eu se realiza na relação com o Tu: é tornando Eu que digo Tu" (bid, p. 13). Para Zuben (1979, p. 13), a palavra Eu-Tu, em Buber, "é o esteio para a vida dialógica".

A palavra-princípio Eu-Isso, por outro lado, descreve o tipo de relação marcada pela finalidade, pelo interesse, que consequentemente levam à objetificação do outro (Buber, 1979). Com isso, não há reconhecimento de sua exclusividade, de sua aura. Pelo contrário, o outro é visto de forma genérica e despersonificada, como um conjunto de qualidades e papéis. Isso mantém a relação no passado, naquilo que o outro representa para a memória: "objeto não é duração, mas estagnação, parada, interrupção, enrijecimento, desvinculação, ausência de relação, ausência de presença" (Buber, op. cit., p. 14). Para Zuben (1979, p. 36), a palavra Eu-Isso "instaura (...) o lugar e o suporte da experiência, do conhecimento, da utilização".

O Isso da relação Eu-Isso, como qualquer outra "coisa", é mantido a distância, é manipulável e explorável. Ao manipular e explorar, o Eu da mesma relação não se reconhece como um ser, mas como "modo de ser" (idem, ibid., p. 74), da mesma forma cristalizado no passado. Como resultado, a ação do homem no mundo do Isso não é capaz de fazer mais do que simplesmente perpetuá-lo.

Mas as duas condições descritas não podem ser consideradas permanentes. Pelo contrário, relacionam-se de forma alternada, entre "atualidade" e "latência", 
"não como se fossem sempre estados que se alternam nitidamente, mas amiúde, são processos que se entrelaçam confusamente numa profunda dualidade" (Buber, 1979, p. 19 e 20).

Assim, "a contemplação autêntica é breve" (p. 19). Por isso mesmo, a relação Eu-Isso deve ser considerada como necessária. Ela se torna negativa quando domina o homem, que passa a viver completamente sob seus desígnios, que perde sua responsabilidade e poder de decisão (Zuben, 1979). Segundo Buber (op. cit., p. 39), “o homem não pode viver sem o Isso, mas aquele que vive somente com o Isso não é homem".

A interpretação de Buber (1979) para o diálogo como sendo a relação em reciprocidade, sem interposições e no tempo presente, estabelece ao mesmo tempo a base filosófica deste trabalho, bem como o horizonte utópico que se deseja promover.

Entretanto, para os contextos de delineamento e implementação de políticas públicas em EA, a questão que surge é se o diálogo se dá apenas na espontaneidade, emergindo momentaneamente da "latência" (p. 19) para, em seguida, retornar a esse estado, como coloca Buber (op. cit.), ou se seria possível, de alguma forma, fomentá-lo. No final do século XX, alguns autores passaram a se debruçar sobre essa questão, como será explicitado a seguir.

\section{A teoria operacional do diálogo}

A teoria operacional do diálogo é recente. Iniciativas de implantação de projetos de fomento ao diálogo e de pesquisas sobre o tema começaram apenas em meados da década de 1980 e passaram a indicar que, como uma forma específica de conversa e quando bem orientado, o diálogo pode levar a resultados importantes (Yankelovich, 2001). ${ }^{4}$

A teoria operacional do diálogo inicia-se com Bohm (2005), que produz uma base filosófica que leva a uma compreensão do conceito diferente do senso comum. Para o autor, a partir da análise etimológica do termo dialogos (dia = através e logos $=$ palavra, ou significado), diálogo significa uma "corrente de significados que flui entre nós e por nosso intermédio" (p. 34). Assim, o diálogo para Bohm ocorre quando for percebido um fluxo subjacente unindo os participantes da conversa.

Isaacs (1999), ao proceder à mesma análise etimológica, oferece ainda outra possibilidade, não muito diferente da de Bohm: a de que a palavra remete à relação. Ambos, como se vê, nesse ponto, aproximam-se do significado filosófico proposto por Buber (1979), ou seja, valorizam a relação, o fluxo, o que está entre. O sentido trazido por Bohm (2005) e Isaacs (1999) difere o diálogo tanto do senso comum, que em geral o considera uma conversa entre "dois" (Bohm, 2005), quanto de outras formas de conversa, como debate, consenso, discussão ou negociação. 
Debate, cuja raiz é "bater", é a forma de conversa na qual os participantes tentam vencer. Para tal, acessam vários dispositivos de proteção, visando defender suas posições e, sempre que possível, atacar as dos outros. É uma arena de batalha, cujo único resultado satisfatório é a vitória (Isaacs, 1993).

A raiz de consenso significa "se sentir junto" (idem, ibid., p. 26) e designa uma conversa na qual se busca de forma racional a limitação do número de opções existentes e a valorização daquelas que são aceitas pela maior parte do grupo (Isaacs, 1999). Como tal, silencia as várias alternativas mais distantes do núcleo da tolerância.

Discussão, por sua vez, é um tipo de conversa na qual os diferentes pontos de vista presentes são analisados separadamente, de acordo com sua raiz, divisão ou afastamento. Como em um debate, o objetivo da discussão é sobrepujar o oponente e impor sobre ele o seu ponto de vista (Bohm, 2005). Por fim, a negociação é a forma de conversa, na qual arranjos são feitos no sentido de se alcançar um resultado satisfatório a todos os presentes. Nesse caso, os participantes dispõem de margens de manobra que, nos momentos de impasses, permitem concessões, mas mantêm um núcleo duro de interesses que não pode ser alterado (idem, ibid.).

Todas as conversas aqui descritas apresentam uma característica comum: os participantes querem manter seus interesses intocados e impô-los sobre os demais, desejam "ganhar" a batalha. O enfoque se mantém nas extremidades, na individualidade, nos interesses de cada um. Ademais, são conversas nas quais não há aprendizado, pois os núcleos dos interesses não são tocados. Apesar de importantes e presentes no dia a dia, são conversas com resultados limitados (Bohm, 2005).

O diálogo, para Bohm (1999; 2005), é diferente. É a forma de conversa na qual existe espaço para que os participantes percebam e desafiem suas pressuposições de raiz, que são construídas ao longo de suas vidas e com as quais formam um senso de compreensão da realidade, ou seja, seus paradigmas. O diálogo é, então, uma possibilidade de desafio da natureza dos paradigmas individuais e coletivos (Isaacs, 1993).

Morin (1990, p. 15) descreve paradigma como "princípios ocultos que governam a nossa visão das coisas e do mundo sem que disso tenhamos consciência". As pressuposições de raiz, da mesma forma, atuam, em geral, inconscientemente, mas são tão arraigadas aos sujeitos que se confundem com suas próprias identidades. Assim, quando desafiadas, são defendidas energicamente, gerando entrincheiramento e a sensação de batalha já descrita (Isaacs, 1999; Bohm, 2005).

Quando a forma de conversa não possibilita que essas pressuposições sejam localizadas e explicitadas, não há uma melhor compreensão sobre elas. Assim, as origens das discordâncias se mantêm (Isaacs, 1999; Bohm, 2005). Portanto, enquanto tais participantes tiverem que conversar, por exemplo, porque trabalham juntos, 
suas conversas serão limitadas por suas pressuposições, e para evitar que novos encontros se transformem também em disputas, suas relações se manterão em níveis cada vez mais superficiais.

O diálogo, diferentemente, é um convite ao conhecimento e reconhecimento não só dos pressupostos (individuais e coletivos) que dão fundamento a uma opinião, mas também dos processos por trás deles (Bohm, 2005). É uma forma de investigação compartilhada (Isaacs, 1999), com o objetivo de construir uma comunicação coerente e verdadeira (Bohm, op. cit.). No diálogo, não há apenas um vencedor. Quando um vence, todos vencem (idem, ibid.).

Portanto, o diálogo ocorrerá quando os participantes forem capazes de colocar as pressuposições de raiz, suas e dos outros, em suspenso (Bohm, 1999; 2005), o que significa não colocar as ideias em prática e nem suprimi-las, apenas ver o que elas significam (Bohm, 2005). E essa investigação, esse desvelamento das pressuposições pode provocar importantes mudanças nos sentidos que as pessoas atribuem ao mundo (Bohm, 1999). Como coloca Isaacs (1999), a prática do diálogo não visa apenas à conversa, mas a ação, particularmente a ação coletiva.

Com isso, espera-se que o processo de diálogo forme o fluxo de significados já referido: um pensamento coletivo novo, emergente na diversidade e inexistente para as partes antes do processo (Isaacs, op. cit.). É a oportunidade para que os participantes possam reduzir o apego as suas certezas, baixar suas defesas e ir além das superficialidades que caracterizavam as conversas anteriores (Yankelovich, 2001).

Isso não quer dizer que os conflitos existentes entre os participantes estarão sanados ou que haverá a formação de um consenso e/ou de harmonia. Algumas críticas ao diálogo em processos de políticas públicas centram-se exatamente nesse argumento de que, ao se dialogar, o que se busca é o consenso, escondendo-se os conflitos de interesse e silenciando e oprimindo as vozes dissonantes (Kaplan, 2010).

Esse tipo de confusão ocorre, em geral, porque os proponentes do diálogo nem sempre desvelam o conceito e, quando uma terminologia não é acompanhada de um esclarecimento conceitual e de uma explicação contextualizadora, deixa-se margem para confusões (Yanchelovich, 2001). Assim, consideram o diálogo a partir do senso comum, como colocado anteriormente, e isso permite tomá-lo como uma ilusão, ingenuidade ou, ainda, estratégia de opressão. Por essa razão, o esclarecimento terminológico é fundamental para aqueles que trabalham com o conceito.

Por outro lado, a negação enérgica ao diálogo pode incorrer em uma situação no extremo oposto, a determinação de uma batalha a partir de pressupostos próprios e certezas cegamente defendidas. Da mesma forma que a falsa harmonia, essa postura leva também a uma polarização, a uma estagnação argumentativa (Isaacs, 
1999). Em ambas, perde-se a oportunidade do aprendizado e da vivência do conflito como possibilidade pedagógica e também de construção, como apresentado por Malagodi (2007).

O diálogo, portanto, não visa ao consenso, tampouco à resolução de conflitos (Isaacs, 1999). Pelo contrário, o resultado de um processo de diálogo pode ser uma melhor compreensão das discordâncias, da demarcação dos pontos de vista em jogo, para todas as partes envolvidas (Yanchelovich, 2001), ou, ainda, da "importante zona intermediária da dúvida, da incerteza, e a percepção de temas que precisam ainda ser trabalhados ou deixados" (Spink, 2003, p. 182). O esforço do diálogo visa, sobretudo, à convivência genuína na diferença (Isaacs, 1999).

Entretanto, leva-se em consideração que várias situações, oportunidades de aprendizado, construção e convergência são perdidas simplesmente porque discordâncias, às vezes superficiais, não investigadas a fundo, individual e coletivamente, ganham dimensão e transformam-se rapidamente em situações de impossibilidade de convivência. E isso não apenas no contato entre opiniões extremamente opostas, mas também dentro de grupos e indivíduos de maior proximidade ideológica. Em suma, o diálogo não quer negar o conflito, mas também não quer ficar refém dele (Alves et al., 2010).

Porém, como já demonstrado, a ocorrência de uma conversa não garante que um diálogo esteja em andamento. Para que ocorra, é necessária a construção de um conjunto de condições que possibilitem o pensar junto (Isaacs, 1999), o que é difícil de ser conseguido (Yanchelovich, 2001). Alguns obstáculos para a emergência do diálogo serão abordados a seguir.

O primeiro aspecto que se coloca em meio ao diálogo decorre da fragmentação do pensamento, característica da era moderna, amplamente discutida por Bohm (1995; 1999; 2005) e já mencionada na primeira parte deste texto. Para o autor, a fragmentação artificial atribuída à realidade e depois naturalizada permite a percepção de que é possível que se tenha uma visão do real em sua totalidade. A isso sucede a noção da certeza acerca de algo, o que consequentemente impossibilita a convivência com outras certezas/opiniões divergentes. Tal cenário leva ao posicionamento de combate já citado, em que os interesses na conversa centram-se nas partes, cada um focado em encontrar as brechas que deslegitimam o outro, com a finalidade de sobrepujá-lo. Opiniões são estereotipadas e aqueles que as emitem passam a ser reconhecidos exclusivamente por meio desses estereótipos. O diálogo enseja uma crítica por trás desses estereótipos, na busca das "pessoas de carne e sangue" (Yankelovich, 2001, p. 105).

Isaacs (1999) comenta os riscos que explicam a relutância em se promover uma investigação das próprias certezas, já que, historicamente, elas permitiram a 
edificação da compreensão de ordem da realidade. Mergulhar nelas é, portanto, arriscar-se a um desafio que pode ser desestruturador, ameaçador, principalmente porque não se conhece o ponto de chegada.

Por outro lado, reconhecer os limites das próprias percepções significa reconhecer a legitimidade do outro, o que, automaticamente, pressupõe um processo no qual diferentes opiniões são envolvidas, o que pode também ser problemático do ponto de vista operacional em um grupo.

Ainda, em uma conversa com "lados", centrada no outro, não há atenção aos próprios processos subjacentes de pensamento, que operam diversas estratégias e bloqueios e tendem a afastar as pessoas de assuntos que desafiam seus paradigmas e aproximá-las de outros que os confirmam. Segundo Bohm (2005), a inconsciência quanto à existência desses processos subjacentes de pensamento, dos quais os conteúdos do pensamento emergem, leva a essa dificuldade de autoanálise.

Um segundo obstáculo ao diálogo diz respeito aos papéis sociais que as pessoas carregam e que acabam por defini-las, para si e para os outros. Assim, a pessoa deixa de ser ela mesma e passa a ser um estereótipo, uma visão generalizada, cristalizada na memória, que carrega consigo uma série de significados que a antecedem. Eles impedem a visão do outro na "absoluta singularidade" de Brandão (2007) e no "tempo presente" de Buber (1979). Também carregam as assimetrias de poder que impedem a reciprocidade. Como colocou Buber (op. cit.) sobre a relação Eu-Isso, os papéis sociais fazem parte das pessoas, não se vive sem eles, mas não são as pessoas, a sua humanidade.

Em terceiro lugar, um aspecto abordado por Schein (1993), como obstáculo ao diálogo, provém de uma espécie de contrato tácito estabelecido socialmente, segundo o qual a ordem social de um grupo é mais valorizada do que a externalização de fatos e informações que podem tumultuá-la de alguma forma; apesar de claramente permitir o convívio social, isso mantém as relações, na verdade, em um nível de superficialidade que impede que se tenha uma melhor compreensão do que, de fato, está se passando com o grupo. Eventuais conflitos, cuja lida poderia resultar em uma maior coesão entre o grupo, ficam evitados. Esse é o tipo de consenso que, na realidade, esconde as assimetrias e diferenças presentes entre as pessoas.

De forma extrema, o diálogo é impossibilitado em situações em que há a presença de interesses e pontos de vista que são irreconciliáveis e que não demonstram abertura a priori para a conversa (Yanchelovich, 2001).

Ponto de partida para a ocorrência de diálogo é a disposição para que as pessoas compartilhem críticas, queiram ouvir, ver o mundo e ser visto pelos olhos dos outros (Bohm, 1999). Uma questão implícita na teoria do diálogo, no entanto, é que 
não é possível que se trace uma linha, a princípio, que determine essa irreconciliabilidade. Essa afirmação é corroborada empiricamente pelo relatório de projeto disponibilizado por Isaacs (s.d.), no qual são apresentados os resultados bem-sucedidos de um longo processo de diálogo envolvendo a administração e o sindicato de uma empresa metalúrgica dos Estados Unidos. Esses dois órgãos haviam cultivado fortes discordâncias, consideradas irreconciliáveis por ambos, por mais de quarenta anos.

O que foi feito nessa experiência, e em outras que estão disponíveis no relatório, foi a construção de um espaço de diálogo (Bohm, 2005), ou seja, um ambiente em que a diversidade existente possa emergir de forma segura, sem medo de represálias pelo que se acredita, sem agenda ou objetivo especial. Assim, não existe garantia para a ocorrência do diálogo, mas o esforço pela criação de um espaço no qual ele fique possibilitado. Também, não há um modelo para esse espaço, mas algumas práticas já indicam aspectos que podem ajudar a determinar se as condições para o diálogo estão ou não presentes (Isaacs, 1999). Esse é um dos desafios postos para aqueles que trabalham ou desejam trabalhar com o tema.

\section{Conclusão}

O Tratado da Educação Ambiental para Sociedades Sustentáveis e Responsabilidade Global (Fórum Internacional de Organizações Não Governamentais e Movimentos Sociais, 1992), documento que destaca fortemente a relação da educação ambiental com a valorização da diversidade, da participação e do diálogo na construção da democracia, é um grande influenciador das políticas públicas produzidas em âmbito federal no Brasil a partir do Pronea. Assim, fortalece-se no país um processo de incentivos para que educadores e educadoras ambientais não apenas se envolvam cada vez mais com os aspectos pedagógicos da educação ambiental, mas também busquem mecanismos, a partir de seus contextos locais, para criar condições estruturais para que tais processos sejam enraizados, ampliados e se tornem, na medida do possível, permanentes.

Essa postura das políticas públicas federais de EA se apoia em uma tendência epistemológica que parte de uma visão participativa de políticas públicas, as considera como resultado de conflitos de forças e, portanto, incentiva encontros de pluralidades, mediados pelo diálogo, para suas construções.

Os objetivos, portanto, com a constituição desses espaços de encontro entre diferentes são a repolitização da vida comunitária (Santos, 2007) e a radicalização da dimensão participativa da democracia (Santos, 2003), por meio da formação de "comunidades interpretativas e de aprendizagem" (Brasil, 2006b), espaços que 
permitem a emergência de conflitos e diálogos horizontais e, consequentemente, colaboram com a criação de constelações de saberes e práticas (Santos, 2002).

Assim o Pronea, o Profea e outras políticas públicas federais abriram para educadores e educadoras ambientais um novo universo, que é o envolvimento em processos de elaboração e implantação de políticas públicas. Isso demanda deles um conjunto de conhecimentos e habilidades, em geral, não presentes em seus processos de formação. Uma dimensão desses conhecimentos e habilidades se refere à construção de espaços em que o diálogo possa acontecer. Assim, faz-se necessário um aprofundamento nas singularidades do conceito, objetivo do presente trabalho.

Este artigo iniciou a abordagem do conceito de diálogo remetendo-se ao filósofo Martin Buber e a sua interpretação da relação dialógica como aquela que emerge livre de interposições entre os sujeitos, no tempo presente, reconhecendo a exclusividade do outro. Apesar de, posteriormente, o artigo seguir o rumo da operacionalização do diálogo, que se diferencia da espontaneidade de Buber, permanece ancorado em suas bases filosóficas e horizonte utópico.

Conforme já demonstrado, um mergulho no conceito de diálogo poderá trazer resultados inesperados para aqueles que normalmente lidam com o conceito a partir do senso comum, o que pode auxiliar as suas práticas.

Como abordado por Isaacs (1999), o diálogo tem um grande potencial como instigador de democracia. Apesar de ainda enfrentar resistências, o contexto atual de maior conscientização política por parte do cidadão comum, a existência cada vez maior de instrumentos legais que exigem participação pública em processos de tomada de decisões (comitês, fóruns, entre outros), as percepção das limitações de alcance de processos de políticas públicas (Spink, 2003) e também de construção do conhecimento (Funtowics \& Ravetz, 2000) que negligenciam o diálogo, além de brechas na burocracia (Isaacs, 1999), têm aumentado as chances da participação de homens e mulheres em processos dialógicos de composição das políticas que influenciarão suas próprias vidas.

E como processos de diálogo, conforme propostos pela operacionalização, contribuem para o afloramento de novos saberes na experiência pública coletiva, podem ser catalisadores de formas criativas de engajamento e de estabelecimento de parcerias entre governos e a sociedade civil nos processos de delineamento e implantação de políticas públicas (Yankelovich, 2001).

São necessários, no entanto, maiores aprofundamentos na teoria operacional do diálogo em si e na sua relação com processos de delineamento e implementação de políticas públicas. Espera-se, com este trabalho, colaborar com essa construção e estimular outros educadores e educadoras ambientais a se engajarem com o conceito e incorporá-lo, com maior consciência, em suas vidas. 


\section{Notas}

1. A polarização referida aqui visa apenas a demarcar extremos estereotipados de um conjunto complexo de combinações e deve ser entendida como tal.

2. Em seu texto, o autor mantém o nome em Inglês: "Policy cycle".

3. Ver o número zero da Revista Brasileira de Educação Ambiental (2004).

4. Autores como Yanchelovich (2001) e Isaacs (1999), apesar de promoverem a operacionalização do diálogo, remetem-se também às bases filosóficas de Buber.

\section{Referências}

ALVES, D.M.G. et al. Em busca da sustentabilidade educadora ambientalista. Ambientalmente Sustentable, Coruña, v. 5, n. 9-10, p. 7 - 35, jan./dec. 2010.

BOHM, D. Wholeness and the implicate order. London: Routledge, 1995.

BOHM, D. Unfolding meaning: a weekend of dialogue. London: Routledge, 1999.

BOHM, D. Diálogo: comunicação e redes de convivência. São Paulo: Palas Athena, 2005.

BRANDÃO, C.R. Prefácio. In: FERRARO JR. L.A. (Org). Encontros e caminhos: formação de educadoras (es) ambientais e coletivos educadores. Brasília, DF: MMA/DEA, 2007. v. 2, p. 3-13.

BRASIL. Constituição (1988). Constituição da República Federativa do Brasil. Diário Oficial da União, Brasília, DF, 5 out. 1988.

BRASIL. Lei n. 6.938 de 31 de agosto de 1981. Dispõe sobre a Política Nacional do Meio Ambiente, seus fins e mecanismos de formulação e aplicação e dá outras providências. Diário Oficial da União, Brasília, DF, 2 set. 1981.

BRASIL. Lei n. 9.795 de 27 de abril de 1999. Dispõe sobre a educação ambiental, institui a Política Nacional de Educação Ambiental e dá outras providências. Diário Oficial da União, Brasília, DF, 28 abr. 1999.

BRASIL. Programa Nacional de Educação Ambiental. 3. ed. Brasília, DF: Ministério do Meio Ambiente; Ministério da Educação, 2005.

BRASIL. Orgão Gestor da Politica Nacional de Educação Ambiental (PNEA). Portfólio do Órgão Gestor da Política Nacional de Educação Ambiental. Brasília, DF: PNEA, 2006a. (Documentos, n. 7).

BRASIL. Orgão Gestor da Política Nacional de Educação Ambiental (PNEA). Programa Nacional de Formação de Educadoras(es) Ambientais: por um Brasil educado e 
educando ambientalmente para a sustentabilidade. Brasília, DF: PNEA, 2006b. (Documentos Técnicos, n. 8).

BUBER, M. Eu e tu. 2. ed. São Paulo: Cortez, 1979.

CASTELLANO, M.; SORRENTINO, M. Participação social e diálogo entre agricultura e meio ambiente na construção de políticas públicas voltadas à restauração de matas ciliares. In: SORRENTINO, M. et al. Educação ambiental e políticas públicas. Curitiba: Appris, 2012. (no prelo).

CLINE, K.D. Defining the implementation problem: organizational management versus cooperation. Journal of Public Administration Research and Theory, Oxford, v. 10, n. 3, p. 551-572, 2000.

FÓRUM INTERNACIONAL DE ORGANIZAÇÕES NÃO GOVERNAMENTAIS E MOVIMENTOS SOCIAIS. Tratado das ONGs. Rio de Janeiro, 1992. p. 198- 201.

FREY, K. Políticas públicas: um debate conceitual e reflexões referentes à prática da análise de políticas públicas no Brasil. Planejamento \& Políticas Públicas, Brasília, DF, n. 21, p. 211-259, jun. 2000.

FUNTOWICS, S.O.; RAVETZ, J.R. La ciencia posnormal: ciência con la gente. Barcelona: Icaria, 2000.

HEIDEMANN, F.G. Do sonho do progresso às políticas de desenvolvimento. In: HEIDEMANN, F.G.; SALM, J.F. (Org.). Políticas públicas e desenvolvimento: bases epistemológicas e modelos de análise. Brasília, DF: UnB, 2009. p. 23-39.

ISAACS, W. Dialogue, collective thinking and organizational learning. Organizational Dynamics, New York, v. 22, n. 2, p.24-39, 1993.

ISAACS, W. Dialogue and the art of thinking together: a pioneering approach to communicating in business and in life. New York: Doubleday, 1999.

ISAACS, W. The Dialogue Project Annual Report 1993-1994. [s.d.]. Disponível em: <http:// www.solonline.org/res/wp/8004.html>. Acesso em: 30 jul. 2010.

KAPLAN, L. Análise crítica dos discursos sobre Estado e sociedade civil nas políticas públicas em educação ambiental. In: ENCONTRO NACIONAL DA ANPPAS, 5., 2010, Florianópolis, Anais... Florianópolis: Anppas, 2010. (CD-ROM).

MALAGODI, M.A.S. Conflitos: conflitos, discórdias, polêmicas, desentendimentos... estorvando a "ordem" conformista e desbloqueando a aprendizagem social. In: FERRARO JUNIOR., L.A. (Org). Encontros e caminhos: formação de educadoras(es) ambientais e coletivos educadores. Brasília, DF: MMA/DEA, 2007. v. 2, p. 71-84. 
MEDINA, N.M. Breve histórico da educação ambiental. In: PÁDUA, S.M.; TABANEZ, M.F. (Org.). Educação ambiental: caminhos trilhados no Brasil. Brasília, DF: IPE, 1997. p. 257-269.

MORIN, E. Introdução ao pensamento complexo. 2. ed. Lisboa: Instituto Piaget, 1990.

MORIN, E. Ciência com consciência. 5. ed. Rio de Janeiro: Bertrand Brasil, 2001.

RAMOS, A.G. A modernização em nova perspectiva: em busca do modelo da possibilidade. In: HEIDEMANN, F.G.; SALM, J.F. (Org.). Políticas públicas e desenvolvimento: bases epistemológicas e modelos de análise. Brasília, DF: UnB, 2009.

REIGOTA, M. Educação ambiental: fragmentos de sua história no Brasil. In: NOAL, F.; REIGOTA, M. Tendências da educação ambiental brasileira. Santa Cruz do Sul: Edunisc, 1998. p. 229-258.

REZENDE, U.S. Comentário: antropologia fundamental e teoria das organizações. In: HEIDEMANN, F.G.; SALM, J.F. (Org.). Políticas públicas e desenvolvimento: bases epistemológicas e modelos de análise. Brasília, DF: UnB, 2009. p. 79-84.

SALM, J.F. Comentário: Teorias P e as alternativas para co-produção do bem público. In: HEIDEMANN, F.G.; SALM, J.F. (Org.). Políticas públicas e desenvolvimento: bases epistemológicas e modelos de análise. Brasília, DF: UnB, 2009. p. 84-92.

SANTOS, B.S. Para uma sociologia das ausências e uma sociologia das emergências. Revista Crítica de Ciências Sociais, Lisboa, n. 63, p. 237-280, 2002.

SANTOS, B.S. Pela mão de Alice: o social e o político na pós-modernidade. São Paulo: Cortez, 2003.

SANTOS, B.S. A crítica da razão indolente: contra o desperdício da experiência. 6. ed. São Paulo: Cortez, 2007.

SCHEIN, E.H. On dialogue, culture and organizational learning. Organizational Dynamics, New York, v. 22, n. 2, p. 40-52, 1993.

SORRENTINO, M.; NASCIMENTO, E.P. Universidade e políticas públicas de educação ambiental. Educação em Foco, Juiz de Fora, v. 14, n. 2, set. 2009/fev. 2010.

SORRENTINO, M. et al. Política pública nacional de educação ambiental não formal no Brasil: gestão institucional, processos formativos e cooperação internacional. In: CONFERÊNCIA INTERNACIONAL DE EDUCAÇÃO AMBIENTAL, 4., 2007, Ahmedabad. Anais... Ahmedabad, 2007.

SOUZA, C. Políticas públicas: uma revisão da literatura. Sociologias, Porto alegre, v. 8, n. 16, p. 20-46, jul.-dez. 2006. 
O diálogo em processos de políticas públicas de educação ambiental no Brasil

SPINK, P. Dialogue from a field perspective. In: OLSSON, J; WOHLGEMUTH, L (Ed.). Dialogue in pursuit of development. Stockholm: Almqvist \& Wiksell, 2003. p. $175-188$.

YANCHELOVITCH, D. The magic of dialogue: transforming conflict into cooperation. New York: Touchstone, 2001.

ZUBEN, N.A. Introdução. In: BUBER, M. Eu e tu. 2. ed. São Paulo: Cortez, 1979.

Recebido em 22 de janeiro de 2011.

Aprovado em 15 de maio de 2012. 